\title{
Membrane Contact Sites in Yeast: Control Hubs of Sphingolipid Homeostasis
}

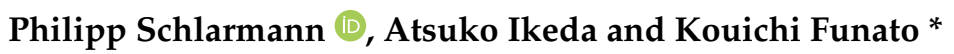 \\ Graduate School of Integrated Sciences for Life, Hiroshima University, Kagamiyama 1-4-4, \\ Higashi-Hiroshima 739-8528, Japan; phschlarmann@gmail.com (P.S.); atsukoikeda@hiroshima-u.ac.jp (A.I.) \\ * Correspondence: kfunato@hiroshima-u.ac.jp
}

Citation: Schlarmann, P.; Ikeda, A.; Funato, K. Membrane Contact Sites in Yeast: Control Hubs of Sphingolipid Homeostasis. Membranes 2021, 11, 971. https://doi.org/10.3390/ membranes11120971

Academic Editor: Rossella Venditti

Received: 18 November 2021

Accepted: 6 December 2021

Published: 9 December 2021

Publisher's Note: MDPI stays neutral with regard to jurisdictional claims in published maps and institutional affiliations.

Copyright: (c) 2021 by the authors Licensee MDPI, Basel, Switzerland. This article is an open access article distributed under the terms and conditions of the Creative Commons Attribution (CC BY) license (https:/ / creativecommons.org/licenses/by/ $4.0 /)$.

\begin{abstract}
Sphingolipids are the most diverse class of membrane lipids, in terms of their structure and function. Structurally simple sphingolipid precursors, such as ceramides, act as intracellular signaling molecules in various processes, including apoptosis, whereas mature and complex forms of sphingolipids are important structural components of the plasma membrane. Supplying complex sphingolipids to the plasma membrane, according to need, while keeping pro-apoptotic ceramides in check is an intricate task for the cell and requires mechanisms that tightly control sphingolipid synthesis, breakdown, and storage. As each of these processes takes place in different organelles, recent studies, using the budding yeast Saccharomyces cerevisiae, have investigated the role of membrane contact sites as hubs that integrate inter-organellar sphingolipid transport and regulation. In this review, we provide a detailed overview of the findings of these studies and put them into the context of established regulatory mechanisms of sphingolipid homeostasis. We have focused on the role of membrane contact sites in sphingolipid metabolism and ceramide transport, as well as the mechanisms that prevent toxic ceramide accumulation.
\end{abstract}

Keywords: sphingolipids; membrane contact sites; metabolism; ceramides; non-vesicular transport; lipotoxicity; yeast; Saccharomyces cerevisiae

\section{Introduction}

Sphingolipids are important components of cellular membranes that exert various functions, depending on their structural maturation and subcellular localization. Sphingolipids are synthesized in the endoplasmic reticulum (ER) and transported to the Golgi, where they are equipped with a variable headgroup. The resulting products are termed complex sphingolipids and are integrated mainly into the plasma membrane (PM), where they contribute to the organelle's barrier function and identity. In addition, PM sphingolipids assemble with sterols and membrane proteins into microdomains that drive many PM-related processes, such as endocytosis, nutrient transport, and $\mathrm{pH}$ maintenance, by limiting lateral movement and increasing the interaction of functional partners [1]. In contrast, simple sphingolipid precursors, such as long-chain bases (LCBs) and ceramides, are not only necessary intermediates for the synthesis of complex sphingolipids but also function as signaling lipids in processes, including cell migration, stress response, senescence, differentiation, and endocytosis [2]. Of special interest are the opposing roles of sphingolipid precursors in determining cell fate for ceramide with pro-apoptotic properties and LCB-1-phosphate anti-apoptotic properties [3,4]. Due to this fact, ceramide has attracted increasing attention as a tumor suppressor lipid, and the mechanisms that regulate ceramide levels have become the subject of intense investigation [5]. The budding yeast, Saccharomyces cerevisiae, has been employed as the model organism of choice to investigate sphingolipid homeostasis, and studies have revealed an extensive kinase network evolving around the target of rapamycin complexes 1 (TORC1) and 2 (TORC2), which senses nutrient levels at the vacuole, as well as lipid homeostasis at the PM, and adjusts sphingolipid synthesis accordingly [6-9]. Other mechanisms contributing to sphingolipid homeostasis 
are sphingolipid breakdown, which takes place in the vacuole, ER, and mitochondria, as well as storage of sphingolipids as acylceramide in lipid droplets (LDs) [10-12]. As these processes involve a variety of organelles, membrane contact sites (MCSs) have been proposed to mediate non-vesicular interorganellar transport of sphingolipids and integrate regulatory mechanisms for sphingolipid homeostasis. In this review, we summarize the metabolic and catabolic pathways of sphingolipids and the regulatory mechanisms that control them, specifically MCSs and non-vesicular ceramide transport. We have focused on studies using S. cerevisiae but also highlight research on mammalian cell lines, when complementation is needed.

\section{Sphingolipid Synthesis, Catabolism, and Trafficking in Yeast}

In S. cerevisiae, the major pathways and enzymes involved in sphingolipid synthesis have already been identified (Figure 1A). Sphingolipid biosynthesis begins with the condensation of cytosolic serine and palmitoyl-CoA by the ER-resident serine palmitoyltransferase (SPT) complex, yielding 3-ketodihydrosphingosine (KDS). The SPT complex contains three subunits: Lcb1, Lcb2, and Tsc3. Because its active site is at the interface of the two catalytic subunits, Lcb1 and Lcb2, facing the cytosol, it is suspected that KDS is incorporated into the outer leaflet of the ER membrane after its synthesis [13-15]. Subsequently, KDS is reduced to dihydrosphingosine (DHS) or, in a following step, hydroxylated to phytosphingosine (PHS), by enzymes that also face the outer leaflet of the ER [16]. DHS and PHS are termed "LCBs,", which act as the backbone of sphingolipids. Both LCB-types can be converted with a CoA-activated very long-chain fatty acid (VLCFA) into dihydroceramide and phytoceramide, respectively, through ceramide synthase. Ceramide synthase is a heteromeric protein complex, containing three subunits, Lag1, Lac1, and Lip1. Lag1 and Lac1 are homologous proteins that feature eight transmembrane domains (TMDs) and a conserved Lag motif, which extends over the 5th and 6th TMDs and presumably harbor the active site of the proteins [17]. Both proteins are functionally similar, but differ in their substrate specificity, with Lag1 being better than Lac1 in converting PHS to phytoceramide [18]. This difference already accounts for the distinct roles of Lag1 and Lac1 in aging and further suggests that each LCB isoform and its derivatives have unique physiological functions [18]. The third subunit of the ceramide synthase Lip1 features a single TMD and exerts its essential function in the complex, through the transmembrane or luminal part of the protein [19]. The topology of ceramide synthase is not understood in detail. However, a model was proposed, in which the catalytic center of the ceramide synthase forms a channel that connects the leaflets of the ER membrane [17]. Translocation between the ER leaflets is essential for both the substrate and product of ceramide synthase. For example, after a series of phosphorylation and dephosphorylation steps, exogenously added DHS is delivered into the inner layer of the ER, where it is used for ceramide synthesis $[20,21]$. Therefore, translocation is necessary to ensure the conversion of endogenously synthesized and exogenously added DHS. Likewise, ceramide is found on both sides of the ER membrane and can be transported by vesicular transport from either side to the next destination of the sphingolipid synthesis pathway, the Golgi. Ceramides present on the cytosolic side are also available for delivery to the Golgi via non-vesicular transport. 


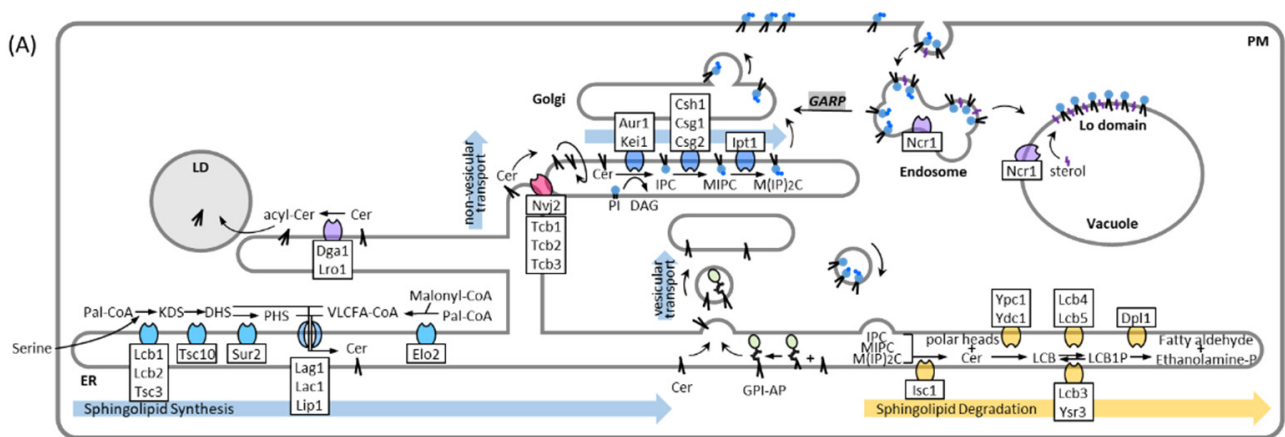

(B)

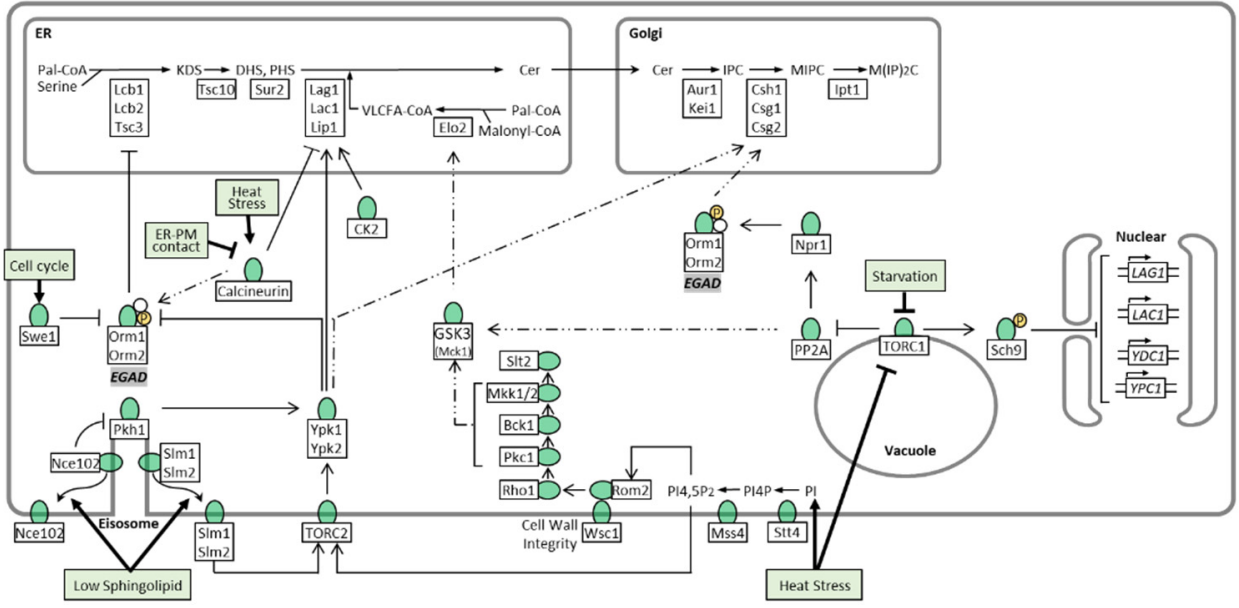

Figure 1. Sphingolipid synthesis, catabolism, and regulation of sphingolipid metabolism. See texts for details. (A) Sphingolipid biosynthesis and catabolism: sphingolipid biosynthesis begins at the ER and ceramide is produced in the ER, before it is transported to the Golgi apparatus. This figure does not depict all possible subclasses of ceramide that arise from hydroxylation, desaturation, and varied chain length. The transport of ceramide from the ER to the Golgi depends mainly on the COPII-mediated vesicular transport, and minorly non-vesicular transport via membrane contact sites (MCSs). Ceramide is converted to complex sphingolipids in the Golgi apparatus, and complex sphingolipids are sorted to the PM and endosome/vacuole by vesicular transport mechanisms. Isc1 cleaves complex sphingolipids, yielding ceramide and a free polar head group. Ceramide is hydrolyzed by ceramidases into LCB and fatty acid, and LCB is phosphorylated by LCB kinases to yield LCB1P, which is degraded by a LCB1P lyase to produce ethanolamine phosphate and fatty aldehyde [22,23]. (B) Regulation of sphingolipid metabolism: kinase and phosphatase signaling from the PM and other organelles regulate the various stages of sphingolipid metabolism. Regulation by proposed but insufficiently verified mechanisms are indicated by a dashed arrow. Abbreviations: palmitoyl-CoA (Pal-CoA), 3-ketosphinganine (KDS), dihydrosphingosine (DHS), phytosphingosine (PHS), long-chain base (LCB), long-chain base 1-phosphate (LCB1P), very long-chain fatty acid (VLCFA), ceramide (Cer), acylceramide (acly-Cer), lipid droplet (LD), GPI-anchored protein (GPI-AP), phosphatidylinositol (PI), diacylglycerol (DAG), phosphatidylinositol (IPC), mannosyl inositolphosphorylceramide (MIPC), mannosyl di(inositolphosphoryl) ceramide (M(IP)2C), ethanolamine phosphate (Ethanolamine-P), Golgi-associated retrograde protein (GARP), endosome and Golgiassociated degradation (EGAD), phosphatidylinositol-4-phosphate (PI4P), and phosphatidylinositol $(4,5)$-bisphosphate $\left(\mathrm{PI} 4,5 \mathrm{P}_{2}\right)$.

The transport of ceramide from the ER to the Golgi depends mainly on the COPII vesicles of the secretory pathway, similar to that of proteins. Glycosylphosphatidylinositol (GPI)-anchored proteins are also synthesized in the ER and transported to the Golgi apparatus by COPII vesicles [24]. Ceramides in the inner layer of the ER are involved in remodeling GPI lipid moieties and seem to coalesce with GPI-anchored proteins during vesicular transport (Figure 1A), as defects in GPI-anchored biosynthesis affect vesicular 
transport of ceramide [25-27]. Conversely, normal ceramide synthesis is required for GPI-anchored protein transport [28]. GPI-anchored proteins are segregated into lipid microdomains in the ER and are sorted into specific transport vesicles [29]. Recent observations, using high-speed, super-resolution live imaging microscopy, have confirmed this model and suggest that the length of ceramide in the raft-like structure is important for the sorting mechanism [30]. Although vesicular transport is the main pathway for ceramide to reach the Golgi, alternative routes exist that maintain some transport even under conditions that block the secretory pathway [31]. This so-called non-vesicular ceramide transport depends on tethering proteins at ER-Golgi contact sites, which facilitate the transfer of ceramide between the surface of the ER and Golgi, which will be discussed later in the review.

Ceramide is converted to complex sphingolipids in the Golgi apparatus. In S. cerevisiae, the major complex sphingolipid is inositol phosphorylceramide (IPC), which is synthesized by IPC synthase via the transfer of an inositol phosphate headgroup from phosphatidylinositol to ceramide. IPC synthase is a protein complex with two known membrane-spanning subunits, Aur1 and Kei1. While Aur1 contains the active site of the complex that faces the lumen of the Golgi [32], Kei1 was shown to be essential for the localization of the complex and its catalytic ability [33]. Because ceramides transported by the non-vesicular pathway are incorporated into the outer layer of the Golgi and used for IPC synthesis [31], it is apparent that a yet unidentified mechanism translocates ceramides to the luminal site. After its synthesis, IPC can be further modified by the mannosylation of its headgroup to form mannose inositolphosphorylceramide (MIPC) or mannose di (inositolphosphoryl) ceramide $\left(\mathrm{M}(\mathrm{IP})_{2} \mathrm{C}\right)$. The synthesis of MIPC depends on the Csh1p/Csg1p/Csg2p complex, and the active site of Csg1p is also predicted in the lumen of the Golgi [34]. Notably, the catalytic subunits of the complex show a different affinity to the dihydro- and phyto-isoforms of IPC, such as the previously mentioned ceramide synthase subunits [35]. Conversion of MIPC to $\mathrm{M}(\mathrm{IP})_{2} \mathrm{C}$ is carried out by Ipt1 [35,36], and complex sphingolipids are transported to the PM. This transport is once more coupled to vesicular transport, as it was shown that the transport of IPC, MIPC, and M(IP) ${ }_{2} \mathrm{C}$ to the PM almost completely stops when vesicular transport is blocked [22,37].

The remodeling of membranes, in response to cell cycle progression and environmental changes, requires enzymes that can reverse each step of the sphingolipid synthesis pathway. Inositol-phosphosphingolipid phospholipase C (Isc1) localizes to the ER and mitochondrial outer membrane and cleaves the polar head group from complex sphingolipids at the $\mathrm{C} 1$ position, yielding phytoceramide and a free head group $[38,39]$ (Figures 1A and 2C). ER and endosomal enzymes degrade phytoceramide in multiple steps, further into PHS and 2-hydroxyhexadecanal, which can be recycled into glycerophospholipid metabolism [40-42]. Defects in sphingolipid degradation and recycling are connected to a variety of human lysosomal storage diseases such as Niemann Pick type C, a fatal neurodegenerative disorder, caused by mutations in the NPC1 or NPC2 gene, which is characterized by lysosomal accumulation of cholesterol and sphingolipids [43]. In yeast, sphingolipid breakdown is also connected to endosomal and vacuolar degradation because deletion of Isc1 leads to defective lysosomal trafficking and vacuolar function $[44,45]$. Cells lacking Isc1 not only build up complex sphingolipids but also some sphingolipid precursors, including very long-chain ceramide species that are presumably derived from increased de novo synthesis [46]. Increased levels of long-chain ceramides activate the catalytic subunit of the protein phosphatase type 2A (PP2A) complex Sit4, which links ceramide and vacuolar homeostasis by negatively regulating protein sorting, vesicular trafficking, vacuole function, and autophagy [44]. Consequently, double deletion of Sit4 and Isc1 restores vacuole function [44]. Sphingolipids not only control endosomal maturation via Sit4 but are also sorted and recycled themselves on endosomes. Ncr1/2, yeast orthologs to the human Npc1/2 proteins, were suggested to sort sphingolipids on endosomes with IPC being directed to the vacuolar membrane, and MIPC and M(IP) $2 \mathrm{C}$ being returned to the Golgi and subsequently transported to the PM [47]. The recycling of PM sphingolipids 
depends on the Golgi-associated retrograde protein (GARP) complex, which tethers retrograde transport vesicles derived from endosomes to the late Golgi [48]. Blocking this pathway induces toxic accumulation of LCBs, which suggests increased degradation of complex sphingolipids in the vacuole [49]. In addition to sphingolipid sorting, Ncr1/2 plays a role in sterol transport from endosomes to the vacuolar membrane to form steroland sphingolipid-enriched raft-like domains that mediate microautophagy [50]. Because GARP deficiency also alters sterol metabolism [49], it seems likely that sphingolipids and sterols are sorted via the same Ncr1/2-mediated mechanism.

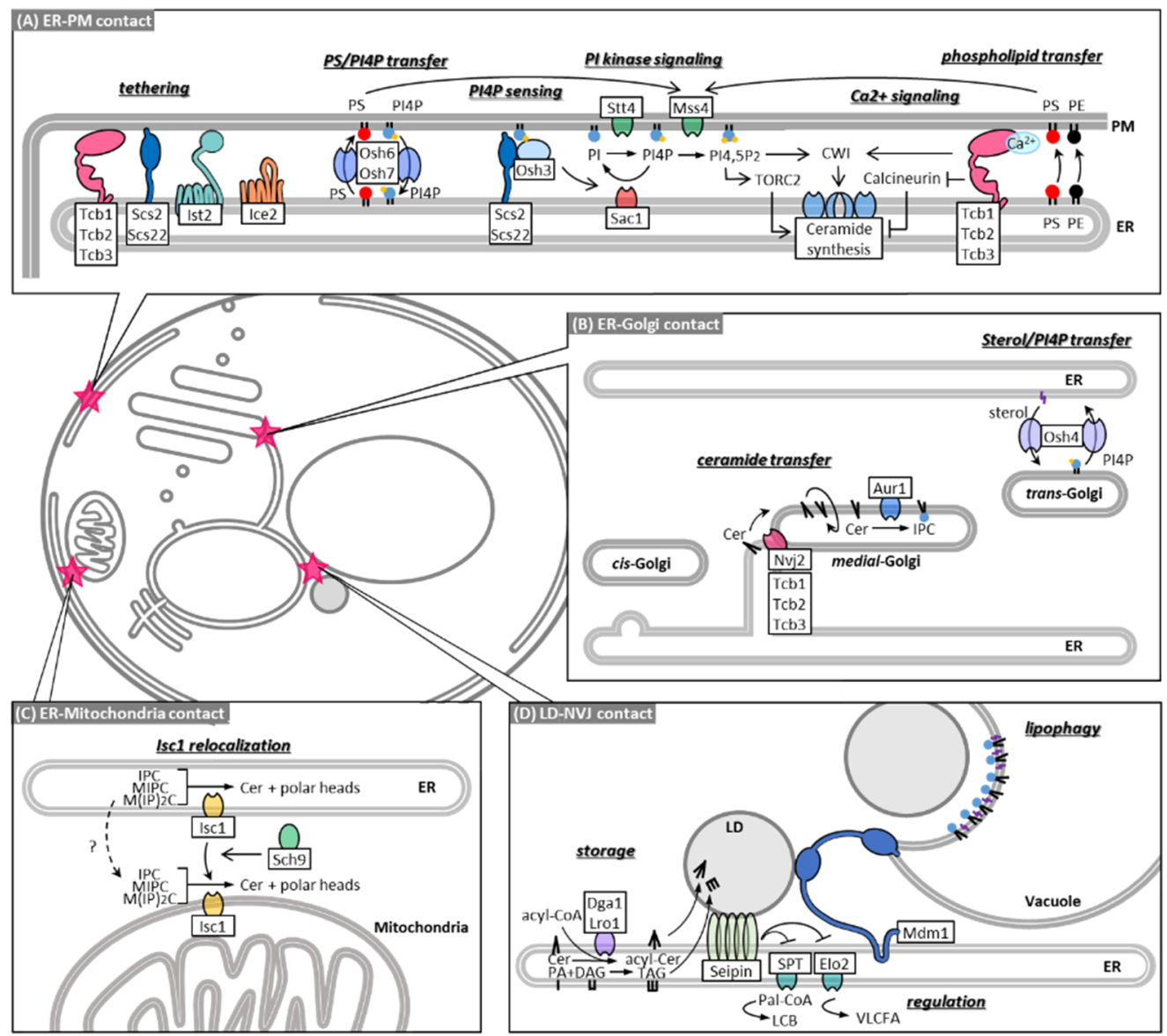

Figure 2. Membrane contact sites in sphingolipid metabolism. Various MCSs are involved in sphingolipid transport and homeostasis. See text for details. (A) ER-PM contact sites are tethered by tricalbins (Tcb1-3), Ist2, Scs2, Scs22, and Ice2. They are essential for $\mathrm{Ca}^{2+}$ signaling and maintaining lipid homeostasis, including PS and PI4P. (B) ER-medial Golgi MCS is proposed to be the site for non-vesicular transport of ceramide. (C) Isc1 localizes to the ER and the mitochondrial outer membrane. Sch9 is essential for the proper translocation of Isc1 from the ER to the mitochondria. (D) Acylceramide converted from ceramide is sorted into the LDs with TAG. Mdm1 acts in the interface between ER, vacuole and LD and spatially defines the site of LD budding. Abbreviations: cell wall integrity (CWI), phosphatidylserine (PS), phosphatidylethanolamine (PE), triacylglyceride (TAG). See Figure 1 for others.

\section{Regulation of Sphingolipid Metabolism}

LCBs, ceramides, and other intermediates in sphingolipid metabolism are vital but potentially toxic signaling molecules [2,3]. Supplying complex sphingolipids to the PM based on need and simultaneously preventing the toxic accumulation of metabolites is an intricate task for cells. It is, therefore, not surprising that many partially interconnected pathways exist that respond to environmental changes and regulate different steps along the sphingolipid synthesis pathway (Figure 1B). The formation of LCBs from serine and 
palmitoyl-CoA by SPT is the rate-limiting step of sphingolipid synthesis and is the main target of regulation. It was shown that LCB synthesis depends on the external uptake of serine, indicating that sphingolipid metabolism is not regulated prior by de novo serine production [51]. The catalytic activity of the SPT complex mainly depends on the presence of two regulatory proteins, Orm1 and Orm2, which inhibit SPT when they are associated with it $[52,53]$. Orm $1 / 2$ are downstream effector proteins of an extensive kinase network that coordinates sphingolipid metabolism with other cellular tasks, such as cell cycle progression, nutrient uptake, and stress response. Here, we break down the pathways of this kinase network targeting Orm $1 / 2$ starting with the initial stimuli:

Sphingolipid deficiency: PM stress caused by sphingolipid deficiency is accompanied by changes in membrane properties and rearrangement of lateral microdomains. Slm1, SIm2, and Nce102 are proteins that localize at steady state to the eisosome, a protein complex that is part of the static PM microdomain, known as the membrane compartment which is occupied by Can1 (MCC) (Figure 1B). Slm1/2 are proteins that localize to the PM by binding to phosphatidylinositol 4,5-bisphosphate (PI4,5P2), whereas Nce102 is an integral PM protein. Depletion of sphingolipids disrupts the lipid and protein organization of the MCC, causing Slm $1 / 2$ and Nce102 to dissociate from the eisosome within the membrane plane. In this way, SIm1/2 become available to bind and activate the PM resident TORC2, which in turn phosphorylates and activates the cytosolic protein kinase Ypk1 [7,54]. Similar to $\operatorname{Slm} 1 / 2$, dissociation of Nce102 alleviates its inhibitory effect on the eisosome resident protein kinases Pkh1 and Pkh2, which in turn phosphorylate Ypk1 as well, but at different sites compared to TORC2-mediated phosphorylation [55]. Ypk1 phosphorylates several targets, including Orm $1 / 2$, triggering their release from the SPT complex and stopping SPT inhibition $[7,53,56]$. Phosphorylation of Orm $1 / 2$ not only causes the proteins to dissociate from the SPT complex but leads to their degradation, via the recently identified endosome and Golgi-associated degradation (EGAD) pathway [57]. In this pathway, phosphorylated Orm2 is exported to the Golgi and endosomes, where it is selectively polyubiquitinated by the Dsc ubiquitin ligase complex, extracted from the membrane by the unfoldase Cdc48, and finally degraded by the proteasome [57]. Degradation of already inactivated Orm2 is necessary because accumulation of Orm2 can divert Ypk1 activity away from other important targets, such as ceramide synthase [58]. Unlike the SPT complex, which depends on Orm $1 / 2$ interaction, ceramide synthase and many other key enzymes in sphingolipid biosynthesis are regulated by direct phosphorylation through protein kinases. Both the ceramide synthase subunits Lag1 and Lac1 are phosphorylated by Ypk1 to activate ceramide synthesis [58,59]. Consequently, TORC2/Ypk1 action controls the first two consecutive steps of sphingolipid synthesis, which ensures a coherent flux of metabolites [58] and provides a feedback mechanism, in response to sphingolipid depletion [7]. Moreover, Ypk1 was suggested to further regulate complex sphingolipid synthases such as Csh1 and Sur1 as these enzymes are phosphorylated at Ypk1 typical phosphorylation motifs, in response to myriocin-induced SPT inhibition [60].

Cell cycle progression and growth: The cell cycle checkpoint kinase Swe1 induces Orm1/2 phosphorylation and LCB synthesis independently of Ypk1 [61]. Swe1 is activated and halts cell cycle progression in response to defective lipolysis, which is a source of lipid precursors for sphingolipid synthesis [62]. Therefore, Orm1/2 phosphorylation by Swe1 could be a feedback loop to maintain a steady supply of LCBs. Moreover, casein kinase 2 (CK2), a major regulator of various pro-growth cellular events and suppressor of apoptosis $[63,64]$, promotes ceramide synthesis by directly phosphorylating the $C$-terminal cytoplasmic domains of the ceramide synthase subunits Lag1 and Lac1 [65]. CK2 dependent phosphorylation of ceramide synthase was suggested to maintain its localization to the ER membrane via the COP I-dependent C-terminal dilysine ER retrieval pathway [65].

Starvation: Orm1/2 are also phosphorylated via the TORC1 pathway (Figure 1B), which senses amino acids at the vacuole and adjusts cellular metabolism in response to amino acid starvation [66]. TORC1 is inhibited under these conditions and is unable to phosphorylate a variety of downstream targets, including the cytosolic protein phosphatase 
type 2A (PP2A), which is suppressed by TORC1 at steady state [67]. PP2A is responsible for dephosphorylation and activation of the protein kinase Npr1, which in turn phosphorylates Orm1/2 but at different sites compared to Ypk1 [6]. In contrast, Npr1 mediated Orm1/2 phosphorylation does not affect LCB synthesis, but instead activates Orm1/2 to promote the synthesis of complex sphingolipids downstream of the SPT complex through an unidentified mechanism [6]. Because increased complex sphingolipid levels at the PM facilitate the integration of amino acid permeases, TORC1 inhibition provides a feedback loop to promote nutrient uptake during starvation [6]. Nevertheless, it was shown that TORC1 controls the early steps of sphingolipid metabolism by mechanisms other than Orm1/2 phosphorylation. The introduced PP2A branch of TORC1 was proposed to control the phosphorylation and activity of the VLCFA elongase Elo2 via Mck1 kinase [68]. The details of this pathway remain unclear, and contradicting reports have been published on whether Mck1 mediated phosphorylation of Elo2 promotes [68] or inhibits Elo2 activity [69]. Furthermore, steady-state levels of sphingolipids are regulated through the Sch9 effector branch of TORC1, which represses the expression of the ceramidase genes YDC1 and YPC1 as well as ceramide synthase genes LAG1 and LAC1 [70]. Conversely, Sch9 seems to mediate hydrolytic ceramide production during diauxic shift, as Sch9 is essential for the proper translocation of inositol phosphospingolipid phospholipase C, Isc1, from the ER to the mitochondria [70]. Whereas the main role of TORC1 is to adjust cellular metabolism to amino acid availability, other stressors regulate TORC1 function as well such as carbon or phosphorous starvation, hyperosmolarity, oxidants and heat [71,72].

Heat stress and cell wall integrity (CWI) defects: Heat stress induces TORC1 sequestration into stress granules, thereby inhibiting TORC1 function in the vacuole and activating sphingolipid synthesis in a way that is similar to starvation [73]. In addition, elevated temperature is another cause of PM stress that induces sphingolipid synthesis by promoting phosphoinositide-signaling at the PM and subsequently activates two parallel responses, the previously introduced TORC2 pathway and the CWI pathway. Phosphatidylinositides give organellar membranes characteristic properties and drive many membrane-related processes by recruiting effector proteins that specifically recognize their phosphorylation patterns [74]. The two characteristic phosphoinositides of the PM are phosphatidylinositol 4-phosphate (PI4P) and PI (4,5)P2, which are synthesized by the subsequent kinase activities of Stt4 and Mss4, respectively. PM phosphoinositides and sphingolipids seem to be mutually regulated because the localization and activity of Mss4 depends on sphingolipid synthesis [75,76]. Conversely, it was shown that the substrate of Mss4, PI4P, accumulates at the PM upon inhibition of sphingolipid synthesis [77]. Heat shock induces a transient increase in PM phosphoinositides, which recruit PI(4,5)P2-binding Slm1/2 proteins as well as Pkh1 to the PM [78,79] and promote the Pkh-dependent phosphorylation of Slm1/2 [80]. Thus, sphingolipid synthesis is activated via the Pkh1-TORC2-Ypk1 pathway. Simultaneously, elevated levels of phosphoinositides recruit the guanine nucleotide exchange factors Rom 1 and 2 to the PM [79], which together with cell-surface sensors Wsc1, 2 and 3 stimulate nucleotide exchange on the small G protein, Rho1, the designated master regulator of the CWI pathway [81]. The CWI pathway controls several stress response mechanisms, including the high osmolarity response pathway, which alleviates the accumulation of aberrant reactive oxygen species caused by heat stress or inhibited sphingolipid synthesis [82-84]. In contrast, it was shown that the VLCFA elongase Elo2 is phosphorylated and inactivated by Mck1 kinase, a presumed downstream effector of the CWI pathway (Figure 1B), and a model was proposed in which CWI signaling is inactivated in response to perturbed sphingolipid synthesis to de-repress Elo2 [69]. However, this model requires additional investigation, as it remains unclear how signals from the PM are transduced to Elo2 and how Elo2 inhibition is coordinated with other CWI functions.

Heat induced sphingolipid synthesis last approximately $30 \mathrm{~min}$ after which LCBs reach near-basal levels $[36,85]$. Timely monitoring of sphingolipid synthesis and Orm2 phosphorylation in response to heat stress revealed that Orm2 phosphorylation decreases when LCBs reach peak levels, while ceramide synthesis peaks 10 min later [86]. As this 
effect is completely diminished by inhibition of SPT and accelerated by exogenously adding LCBs it was proposed that LCBs activate protein phosphatases that act upstream of Orm $1 / 2$ to restore SPT inhibition after the heat response. The protein phosphatase PP2A, which is also activated by ceramides [44], has been proposed to mediate inhibition of Ypk1 [86] or Pkh1/2 [87].

\section{MCSs in Sphingolipid Metabolism}

Cellular organelles maintain several domains that are in juxtaposition with other organelles. In recent years, it has become apparent that these contact sites perform a variety of functions ranging from lipid synthesis and transfer to intracellular processes such as autophagosome formation and membrane fission [88,89]. As sphingolipid metabolism extends over most organelles, the role of these contact sites in sphingolipid transport and homeostasis has been closely investigated. Here, we provide an overview of how the MCSs are directly involved in sphingolipid metabolism.

Contact sites between the cortical ER and PM cover about $45 \%$ of the inner layer of the PM [90-92] and are essential for maintaining PI4P and $\mathrm{Ca}^{2+}$ signaling pathways that control ceramide synthesis (Figure 2A). ER-PM contacts are established by specialized ER-resident transmembrane proteins called tethers, which feature large disordered cytosolic regions that attach to the opposing PM through lipid or protein interactions. Seven tethering proteins have been identified at this site: three tricalbins (Tcb1-3), Ist2, Scs2, Scs22 [90], and Ice2 [93]. Cells show an almost complete loss in cortical ER-PM association when tethers are deleted, which causes reduced growth and perturbations in lipid homeostasis, including accumulation of PI4P at the PM [94], disorganization of PM-sterols [93], and overall reduction in cellular complex sphingolipid levels [90]. Until recently, a favored model was that these effects are accounted for by dysfunctional proteins that localize to the cortical ER and regulate PM-lipid homeostasis in trans. Osh proteins, a conserved family of lipid exchange proteins related to mammalian oxysterol-binding proteins, are the most promising candidates for regulating lipid homeostasis via ER-PM contact sites. Osh proteins directly interact with ER-PM tethers [95], and deletion of Osh proteins causes phenotypes, similar to the deletion of ER-PM tethers, such as PI4P accumulation [93]. Osh5 and Osh8 were proposed to transport phosphatidylserine (PS) to the PM, in exchange with PI4P [96], which is degraded in the ER by the PI4P phosphatase Sac1, thus maintaining a PI4P concentration gradient that powers the lipid exchange [97]. Osh3 functions as a sensor of PM PI4P and can activate Sac1 to act in trans on the PM [95]. In addition, Osh4 was shown to exchange sterols for PI4P between lipid bilayers [98,99], although it is debated whether this transport occurs at the ER-PM or only at ER-Golgi contacts [93] (Figure 2B). Because of their ability to maintain PM levels of PS, PI4P, and possibly sterols, Osh proteins establish a nanoscale membrane lipid environment that promotes PI4P 5-kinase activity and PI $(4,5)$ P synthesis at the PM [94]. Whereas PI $(4,5)$ P synthesis is important for recruitment of Slm1/2 to the PM and TORC2-Ypk1 signaling, it was found that deletion of ER-PM tethers reduced Ypk1 phosphorylation, following heat stress, by only $30 \%$ and did not affect Pkh1 and TORC2 localization to the PM [100]. Therefore, disruption of Osh function in cells without ER-PM tethering likely accounts for PI4P accumulation and disorganization of PM-sterols but cannot explain the overall reduction in complex sphingolipids.

Instead, ER-PM contacts have been suggested to modulate intracellular $\mathrm{Ca}^{2+}$ and calcineurin signaling, which acts antagonistically to TORC2 signaling (Figure 2A). As previously described, the Pkh1-TORC2-Ypk1 pathway is activated in response to heat stress to promote the first two steps of sphingolipid synthesis. In this event, Ypk1 phosphorylates Orm $1 / 2$ to de-repress SPT and phosphorylates Lag1 and Lac1 to activate ceramide synthesis [58]. Simultaneously, heat stress induces $\mathrm{Ca}^{2+}$ influx and $\mathrm{Ca}^{2+} /$ calmodulinmediated activation of the protein phosphatase calcineurin, which reverses Lag1 and Lac1 phosphorylation [58,59]. In addition, calcineurin activates ORM2 transcription [8] and represses Orm $1 / 2$ degradation via the EGAD pathway by promoting dephosphorylation of Orm1 $/ 2$ either directly or indirectly [101]. The opposite roles of TORC2 and calcineurin 
were further demonstrated by the fact that deletion of the calcineurin regulatory subunit $\mathrm{B}$ restored phytoceramide levels in cells containing a temperature-sensitive allele of the TORC2 subunit TSC3 [59]. TORC2 is a major negative regulator of endocytosis [102,103] in contrast to $\mathrm{Ca}^{2+}$ and calcineurin, which promote endocytosis universally in neuronal and non-neuronal secretory cells [104] and are suspected to act in the same manner in yeast. Because endocytosis takes place on cortical ER-free PM zones [105], it was speculated that by extension of dynamic ER-PM contacts, $\mathrm{Ca}^{2+}$ and calcineurin activity could be contained [100]. This is supported by the fact that cells with deleted ER-PM tethering proteins showed increased cytoplasmic $\mathrm{Ca}^{2+}$ and calcineurin activity [100]. Among the ER-PM tethering proteins the tricalbins seem to be possible candidates to drive this process since they have been suggested before as calcium effector proteins. Tricalbins feature several C2 calcium-binding domains [90] and possess cross membrane phospholipid transfer capabilities that are increased in the presence of calcium [106]. In addition, cells lacking Tcb1/2/3 display only a small reduction in ER-PM association but show strong defects in PM integrity following heat shock, which induces calcium signaling [90]. A very recent study showed that, upon stress induction, tricalbins promote non-vesicular phosphatidylserine and phosphatidylethanolamine transport from the ER to the PM [107]. Moreover, Tcb3 co-localizes upon heat stress with the PM protein Sfk1 which is important for PM phospholipid homeostasis and tricalbins mediate the heat-induced recruitment of the CWI factor Pkh1 to the PM [107]. Taken together, ER-PM tethering proteins seem to serve not only as physical membrane bridges, which promote the action of effector proteins acting in trans but contribute themselves as effectors and mediators to the TORC2/ $\mathrm{Ca}^{2+}$ rheostat and CWI pathway which control sphingolipid homeostasis.

Despite their evident role in maintaining lipid homeostasis, the loss of ER-PM contact sites does not affect cellular growth. A study on synthetic lethal mutations in a strain lacking ER-PM contact sites identified components of the endosomal sorting complex required for transport (ESCRT) III complex as essential mediators of lipid homeostasis when tethering fails [108]. The ESCRT machinery was originally known to drive the formation of multivesicular bodies for endosomal degradation of integral membrane proteins [109]. In this pathway, ESCRT III filaments are nucleated by earlier ESCRT complexes at cargoenriched sites to form a scaffold that invaginates the membrane and buds vesicles into the lumen of the endosome. The vesicles are then released by Vps4 mediated membrane scission accompanied by ATP consumption. Later studies reported that the ESCRT machinery is employed for membrane remodeling at other sides as well [110]. Schmidt et al. showed that the ESCRT III complex and Vps4 are recruited to the PM to maintain membrane integrity, in response to reduced membrane tension and TORC2 inhibition [101]. Conversely, deletion of Vps4 causes hypersensitivity to PM stress, deregulated calcineurin signaling, and activation of TORC2 signaling as a counter measure to calcineurin-inhibited sphingolipid synthesis [101]. Therefore, such as ER-PM contact sites, ESCRT III/Vps4 acts as a mediator of the TORC2 $/ \mathrm{Ca}^{2+}$ rheostat and possibly provides a back-up mechanism when ER-PM contacts are deleted. However, the details of this process, especially the role of Vps4, remain elusive, since the deletion of Vps4 in cells lacking ER-PM tethering did not cause synthetic lethality, unlike deletion of ESCRTIII components [108].

The loss of ER-PM contacts under certain conditions is also compensated by vacuolePM contact site formation. It was recently discovered that the PM of living yeast cells forms micron-scale protein-depleted regions termed "void zones" [111]. These domains resemble the artificial, phase-separated regions seen in giant unilamellar vesicles and giant PM vesicles but are in fact maintained by cells in an energy-dependent manner. Their physiological function is yet unknown, and void zones have been observed to date only under very specific conditions, such as in PS-deficient yeast cells grown at high temperatures. Void zones lack association with the cortical ER but instead form contact sites with the vacuole, possibly to prevent membrane integrity defects at the interface of the phase separation which is prone to high membrane permeability [112]. Because the formation of void zones at the PM depends on sphingolipid synthesis [111], void zone- 
vacuole contacts may be involved in regulating sphingolipid metabolism or organization of the PM.

\section{MCSs in Non-Vesicular Transport of Ceramide}

The presence of a non-vesicular ceramide transport mechanism between the ER and Golgi apparatus was first proposed since complex sphingolipid synthesis in the Golgi was maintained at a low level, even after complete block of vesicular trafficking [31]. Both fluorescence and electron microscopic studies have shown that 10-30\% of medial Golgi compartments containing the IPC synthase Aur1 are closely associated with the ER under non-stress conditions in wild-type yeast cells [113]. During ER stress, the ER-medial Golgi contacts increase, suggesting that the ER-Golgi contact is tightly regulated in response to environmental cues. The increase in ER-medial Golgi contact sites involves the tethering protein Nvj2, which is mainly localized at the nuclear envelope-vacuole junction (NVJ) under non-stress conditions but re-localizes to ER-medial Golgi contacts, following ER stress or ceramide overproduction (Figures 2B and $3 \mathrm{~A}$ ). Liu et al. demonstrated that Nvj2 promotes the non-vesicular transfer of ceramides from the ER to the Golgi complex. As an artificial ER-Golgi tether is unable to completely restore ceramide transfer in cells lacking Nvj2, Njv2 may directly facilitate ceramide transport, in addition to functioning as a tether. Although its direct role remains unclear, it has been proposed that the synaptotagmin-like, mitochondrial (SMP) domain of Nvj2 transfers ceramide from the ER to the Golgi, because a mutation in the SMP domain that probably prevents lipid binding fails to facilitate IPC synthesis via non-vesicular ceramide transport [113]. In addition, Nvj2 features a pleckstrin homology (PH) domain. It is likely that the PH domain is necessary for Nvj2 to bind Golgi membranes; although, which lipids and/or proteins are bound and how the localization of Nvj2 is regulated by ER stress remains unknown.

The members of the yeast tricalbin protein family Tcb1, Tcb2, and Tcb3 are orthologs of the mammalian extended synaptotagmin proteins and henceforth also feature an SMP domain. The tricalbins were identified by Manford et al. [90] as tethering proteins that are highly conserved throughout eukaryotes and are localized to the ER where they form contacts with the PM. In a recent study, we found that Tcb3 is recruited to ER-Golgi contact sites during ER stress or when overexpressed [12] (Figures 2B and 3A). Tcb3 preferentially associates with contact sites between the ER and medial Golgi, where Aur1 is localized, compared to contact sites between the ER and cis Golgi or between the ER and transGolgi. Importantly, deletion of tricalbins perturbs IPC synthesis via non-vesicular ceramide transport without affecting ceramide synthesis and IPC synthase activity, implying that tricalbins are involved in non-vesicular ceramide transport. Both the SMP and C2 domains of Tcb3 are required for IPC synthesis, whereas only the C2 domains contribute to the formation of MCS between the ER and medial Golgi. Therefore, similar to the SMP domain of Nvj2, the SMP domains of tricalbins may directly transfer ceramide at ER-medial Golgi contacts.

The deletion of tricalbins results in the accumulation of acylceramide, which is generated from ceramide by O-acyltransferases, Dga1 and Lro1 [12]. Conversion of ceramide into acylceramide is thought as a response to access ceramide accumulation caused by the defect of non-vesicular ceramide transport. As acylceramides are synthesized in the ER and stored with other neutral lipids in LDs (Figure 3A), it is possible that acylceramide stored in the LD may be directly transported to the Golgi via LD-Golgi contact sites, and tricalbins may facilitate the delivery of acylceramide from the LD. Contradicting this model is, however, the fact that isolated ER- and Golgi-enriched membrane fractions can reconstitute non-vesicular ceramide transport process in vitro [31]. It is also possible that acylceramides are transiently present in the ER and are delivered to the Golgi apparatus via the ER-Golgi contact sites. Furthermore, under non-stress conditions, tricalbins and Nvj2 localize to the ER-PM contact and NVJ, respectively [90,114]. Thus, it cannot be ruled out that ceramides are transported from the ER indirectly to the Golgi apparatus via the PM or vacuole. In this regard, it is noteworthy that a fraction of Golgi compart- 
ments associate with the cortical ER that lies near the PM [12] or vacuole [115]. Mutations in Mdm1, an NVJ tethering protein, induce hypersensitivity to a specific sphingolipid synthesis inhibitor [116], suggesting that the NVJ may also play a role in inter-organelle ceramide trafficking. In fact, Mdm1 defines the site of LD budding in the interface between ER, vacuole, and LD by presumably channeling free FAs from locally enriched FA pools into LDs [117] (Figure 2D). Because FAs are converted with DAG into TAGs to be taken up by LDs and TAG synthesis is carried out be the same enzymes that mediate acylceramide synthesis, Mdm1 might be involved in acylceramide transport into LDs as well. Nvj2 and tricalbins are integral ER membrane proteins with a single TM domain and multiple TM domains, respectively [114], and they facilitate non-vesicular transfer of ceramide. Neither deletion of Nvj2 nor tricalbins can completely prevent IPC synthesis via the non-vesicular transport of ceramide $[12,113]$. They may have a parallel cooperative function in non-vesicular ceramide transport (Figure 3A). Otherwise, other proteins are required for the non-vesicular transport process. A study with a reconstituted cell-free system showed that non-vesicular ceramide transport involves heat-sensitive cytosolic protein(s) [31]. In mammalian cells, CERT is a well-described soluble transfer protein that delivers ceramide to the Golgi at the ER-Golgi contact sites [118,119]. Identifying soluble proteins that facilitate non-vesicular ceramide transfer in yeast is an important challenge for uncovering coordinated mechanisms.


Figure 3. Membrane contact sites in non-vesicular transport and lipotoxicity of ceramide. See text for details. (A) Models of non-vesicular ceramide transport: non-vesicular ceramide transport is proposed to occur between the ER and medial Golgi. Under non-stress conditions, tethering protein Nvj2 is mainly localized at the NVJ and tricalbins are localized to the ER, where they form contacts with the PM (lower part). They re-localize to ER-medial Golgi contacts, following ER stress or ceramide overproduction (upper part). SMP domains of Nvj2 and tricalbins likely transfer ceramide from the ER to the Golgi. (B) Mechanical scheme of ceramide-mediated apoptosis and pathways of ceramide removal from the ER: ceramide transfer to the Golgi and conversion into IPC (1), ceramide conversion into acylceramide and storage in the LDs (2), ceramide hydrolyzation into LCB and free fatty acid (3), and LCB transport from the cytoplasmic side toward the extracytoplasmic side [120], probably at ER-PM contact site (4). Abbreviations: mitochondrial apoptosis-induced channel (MAC), nucleus-vacuole junction (NVJ), vacuole and mitochondria patch (vCLAMP), endoplasmic reticulummitochondria encounter structure (ERMES). See Figures 1 and 2 for others.

\section{MCSs and LDs in Ceramide Lipotoxicity}

Perturbations in sphingolipid metabolism are linked to cellular dysfunction and cell death. In fact, in S. cerevisiae, inhibition of IPC synthase activity by aureobasidin A, a specific inhibitor of Aur1, leads to cell death or growth inhibition [121-127]. This is 
thought to be due to the accumulation of ceramides or the reduction of complex sphingolipids [123,124,127-129]. Because excess ceramide is toxic, ceramide levels in organelles are tightly controlled by synthesis, transport, and catabolism. Yeast has three mechanisms for preventing toxic accumulation of ceramide: converting it to complex sphingolipids after transferring it to the Golgi apparatus (Figures $1 \mathrm{~A}$ and $2 \mathrm{~B}$ ), converting it to acylceramide and storing it in the LDs (Figures 1A and 2D), and hydrolyzing it into a free fatty acid and sphingoid base (Figure 1A). Because the deletion of Nvj2, Dga1, and Lro1 leads to a synthetic growth defect [113], ER-Golgi contact-mediated ceramide transport and acylceramide synthesis seems to be redundant in the clearance of toxic ceramides. Combinational mutations of tricalbins and Sec proteins that drive vesicular transport cause a dramatic accumulation of LDs [12], suggesting that vesicular transport from the ER is also important in preventing ceramide stress (Figure 3B). Given that excess ceramides are converted into acylceramides in the ER and acylceramides are incorporated into the LDs [10-12,113], ER-LD contacts may play a role in protection against ceramide toxicity. Consistent with this, a recent study showed that loss of ER-LD contacts results in increased levels of ceramides and their sphingoid precursors [130], even though its effect on acylceramide levels remains unclear. Interestingly, it was suggested that ER-LD contacts are one of the places where sphingoid intermediates are synthesized, and that seipin, an ER protein involved in LD biogenesis, negatively regulates sphingoid production at ER-LD contact sites [130] (Figure 2D). Thus, ER-LD contact sites may help prevent the accumulation of toxic ceramide not only by facilitating the formation of acylceramide and its incorporation into the LD, but also by reducing the levels of sphingoid intermediates. Degradation of ceramides is carried out by two ceramidases, which are integral membrane proteins localized to the ER and have different substrate specificities, such that Ypc1 preferentially hydrolyzes phytoceramide, whereas Ydc1 hydrolyzes dihydroceramide [131]. There is evidence that Ypc1 can rescue the growth defect caused by reduced Aur1 activity, probably by reducing toxic ceramide levels [127]; however, whether the ceramidase activity is regulated at ER-organelle contact sites remains to be investigated.

Ceramide toxicity depends on the hydroxylation state and acyl chain length. Phytoceramide formed by hydroxylation of dihydroceramide at C-4 seems to be less toxic than dihydroceramide [132]. By replacing endogenous ceramide synthases with one of the enzymes from cotton a yeast strain (GhLag1) was engineered that produces $\mathrm{C} 18$ rather than C26 ceramides. GhLag1 cells remain viable, even if AUR1 is deleted, indicating that C18 ceramide is not toxic to yeast cells [129]. How long-chain ceramides drive yeast cell death is unclear, but ceramides were shown to form pores in the outer membrane of isolated mitochondria from mammalian and yeast cells [133-135] (Figure 3B). The formation of such ceramide channels can mediate the passage of cell death signals from mitochondria, such as cytochrome c [136], apoptosis-inducing factor [137], and endonuclease G [138]. ER-mitochondria contacts may facilitate ceramide-mediated mitochondrial apoptosis. Remarkably, ER-mitochondria encounter structure (ERMES) components are required for the acetic acid-induced yeast apoptosis associated with an increase in ceramide levels [136,139]. Similar to mammalian cells [140-142], yeast mitochondria can also form contacts with LD. Such mitchondria-LD contacts may alleviate ceramide toxicity by promoting the transfer of ceramide from the mitochondria to LD or serve as a site to deliver toxic ceramides to the mitochondria to trigger apoptosis. Consistently, LD encompasses ceramides in wild-type cells treated with aureobasidin A or in GhLag1. Most of the ceramides found in LDs isolated from GhLag1 cells are C24 ceramides, even though the most abundant cellular ceramide in the GhLag1 mutant is C18 ceramide, suggesting that excess toxic long-chain ceramides may be segregated in the ER and sorted with acylceramides to the LD [129]. Furthermore, ceramides are found in the vacuole [143], which forms contact sites with mitochondria, called vacuolar and mitochondrial patches (vCLAMP) [144,145], and with LD $[117,146]$, in addition to contact sites with the nuclear ER, called NVJ $[145,147]$. These contact sites may also help to prevent toxic ceramide accumulation. 


\section{Conclusions and Outlook}

Since J. L. W. Thudichum named the backbone of sphingolipids "sphingosin" in 1884 for its enigmatic ("sphinx-like") properties, we have learned a lot about the structures, synthetic pathways, and functions of sphingolipids. Great strides in sphingolipid biology have been made in the past few decades, through studies using yeast. In addition to the identification of genes involved in sphingolipid synthesis and catabolism and the mechanisms of post-translational regulation of sphingolipid synthesis, through phosphorylation and ubiquitination, some tethers that physically bridge the pairs of organelles at the contact sites have recently been demonstrated to play a role in sphingolipid trafficking. However, we are only beginning to appreciate the potential of MCSs as important regulators of sphingolipid homeostasis. We still have a limited understanding of how cells sense the levels of sphingolipids and MCS-mediated processes are regulated and coordinated to maintain sphingolipid homeostasis. Furthermore, the molecular mechanisms of sphingolipid homeostasis at the transcriptional level and their upstream signaling cascades are poorly understood, although some enzymes involved in sphingolipid metabolism have been shown to be transcriptionally regulated [70,148,149] (Figure 1B).

Another issue is the toxicity caused by excess ceramide accumulation. Although there is evidence that a reduction in complex sphingolipid levels causes mitochondriadependent apoptosis [124], direct evidence that excess endogenous ceramides trigger mitochondria-dependent cell death has not yet been shown in yeast. Defining the molecular basis of ceramide-induced yeast cell death will pave the way for a better understanding of the potential roles of MCSs in protection against ceramide toxicity. Certain cellular stresses, such as heat and ER stress, induce an increase in ceramides [85,129,150-152]. Bridging the gap in our understanding of how cells adapt to such stresses, with increased ceramide levels [113,151-154], will provide new insights into the physiological significance of sphingolipids and answer the fundamental questions of why cells use ceramide as a messenger of cell death and require two routes via vesicular and MCS-mediated nonvesicular pathways for ceramide trafficking.

Finally, cells must have mechanisms to sense the quality of membrane sphingolipid composition, which is coordinated by sterol molecules interacting with sphingolipids in the membrane domains [155-157]. As the supply of sterols to membranes and the membrane domain formation are regulated by the transport of sterols through the MCSs [31,158-160], the study of the role of the MCS in sterol homeostasis will provide additional clues to our understanding of the mechanisms of sphingolipid homeostasis.

Author Contributions: All authors contributed to writing of the original draft and review. All authors have read and agreed to the published version of the manuscript.

Funding: This research was funded by the Grants-in-Aid for Scientific Research from the Japan Society for the Promotion of Science, Japan [JP19H02922 and JP21K19088 to K.F].

Institutional Review Board Statement: Not applicable.

Informed Consent Statement: Not applicable.

Conflicts of Interest: The authors declare no conflict of interest.

\section{References}

1. Ziółkowska, N.E.; Christiano, R.; Walther, T.C. Organized living: Formation mechanisms and functions of plasma membrane domains in yeast. Trends Cell Biol. 2012, 22, 151-158. [CrossRef]

2. Hannun, Y.A.; Obeid, L.M. Principles of bioactive lipid signalling: Lessons from sphingolipids. Nat. Rev. Mol. Cell Biol. 2008, 9 , 139-150. [CrossRef]

3. Pettus, B.J.; Chalfant, C.E.; Hannun, Y.A. Ceramide in apoptosis: An overview and current perspectives. Biochim. Biophys. Acta (BBA)-Mol. Cell Biol. Lipids 2002, 1585, 114-125. [CrossRef]

4. Mandala, S.M.; Thornton, R.; Tu, Z.; Kurtz, M.B.; Nickels, J.; Broach, J.; Menzeleev, R.; Spiegel, S. Sphingoid base 1-phosphate phosphatase: A key regulator of sphingolipid metabolism and stress response. Proc Natl. Acad. Sci. USA 1998, 95, 150-155. [CrossRef] [PubMed]

5. Morad, S.A.; Cabot, M.C. Ceramide-orchestrated signalling in cancer cells. Nat. Rev. Cancer 2013, 13, 51-65. [CrossRef] [PubMed] 
6. Shimobayashi, M.; Oppliger, W.; Moes, S.; Jenö, P.; Hall, M.N. TORC1-regulated protein kinase Npr1 phosphorylates Orm to stimulate complex sphingolipid synthesis. Mol. Biol. Cell 2013, 24, 870-881. [CrossRef]

7. Berchtold, D.; Piccolis, M.; Chiaruttini, N.; Riezman, I.; Riezman, H.; Roux, A.; Walther, T.; Loewith, R. Plasma membrane stress induces relocalization of Slm proteins and activation of TORC2 to promote sphingolipid synthesis. Nat. Cell Biol. 2012, 14, 542-547. [CrossRef]

8. Gururaj, C.; Federman, R.; Chang, A. Orm proteins integrate multiple signals to maintain sphingolipid homeostasis. J. Biol. Chem. 2013, 288, 20453-20463. [CrossRef]

9. Olson, D.K.; Fröhlich, F.; Farese, R.V., Jr.; Walther, T.C. Taming the sphinx: Mechanisms of cellular sphingolipid homeostasis. Biochim. Biophys. Acta (BBA)-Mol. Cell Biol. Lipids 2016, 1861, 784-792.

10. Senkal, C.E.; Salama, M.F.; Snider, A.J.; Allopenna, J.J.; Rana, N.A.; Koller, A.; Hannun, Y.A.; Obeid, L.M. Ceramide is metabolized to acylceramide and stored in lipid droplets. Cell Metab. 2017, 25, 686-697. [CrossRef]

11. Voynova, N.S.; Vionnet, C.; Ejsing, C.S.; Conzelmann, A. A novel pathway of ceramide metabolism in Saccharomyces cerevisiae. Biochem. J. 2012, 447, 103-114. [CrossRef]

12. Ikeda, A.; Schlarmann, P.; Kurokawa, K.; Nakano, A.; Riezman, H.; Funato, K. Tricalbins are required for non-vesicular ceramide transport at ER-Golgi contacts and modulate lipid droplet biogenesis. Iscience 2020, 23, 101603. [CrossRef]

13. Mandon, E.C.; Ehses, I.; Rother, J.; van Echten, G.; Sandhoff, K. Subcellular localization and membrane topology of serine palmitoyltransferase, 3-dehydrosphinganine reductase, and sphinganine N-acyltransferase in mouse liver. J. Biol. Chem. 1992, 267, 11144-11148. [CrossRef]

14. Han, G.; Gable, K.; Yan, L.; Natarajan, M.; Krishnamurthy, J.; Gupta, S.D.; Borovitskaya, A.; Harmon, J.M.; Dunn, T.M. The topology of the Lcb1p subunit of yeast serine palmitoyltransferase. J. Biol. Chem. 2004, 279, 53707-53716. [CrossRef] [PubMed]

15. Gable, K.; Han, G.; Monaghan, E.; Bacikova, D.; Natarajan, M.; Williams, R.; Dunn, T.M. Mutations in the yeast LCB1 and LCB2Genes, including those corresponding to the hereditary sensory neuropathy type I mutations, dominantly inactivate serine palmitoyltransferase. J. Biol. Chem. 2002, 277, 10194-10200. [CrossRef] [PubMed]

16. Kihara, A.; Igarashi, Y. FVT-1 is a mammalian 3-ketodihydrosphingosine reductase with an active site that faces the cytosolic side of the endoplasmic reticulum membrane. J. Biol. Chem. 2004, 279, 49243-49250. [CrossRef]

17. Kageyama-Yahara, N.; Riezman, H. Transmembrane topology of ceramide synthase in yeast. Biochem. J. 2006, 398, 585-593. [CrossRef]

18. Megyeri, M.; Prasad, R.; Volpert, G.; Sliwa-Gonzalez, A.; Haribowo, A.G.; Aguilera-Romero, A.; Riezman, H.; Barral, Y.; Futerman, A.; Schuldiner, M. Yeast ceramide synthases, Lag1 and Lac1, have distinct substrate specificity. J. Cell Sci. 2019, 132, jcs228411. [CrossRef]

19. Vallée, B.; Riezman, H. Lip1p: A novel subunit of acyl-CoA ceramide synthase. EMBO J. 2005, 24, 730-741. [CrossRef]

20. Funato, K.; Lombardi, R.; Vallée, B.; Riezman, H. Lcb4p is a key regulator of ceramide synthesis from exogenous long chain sphingoid base in Saccharomyces cerevisiae. J. Biol. Chem. 2003, 278, 7325-7334. [CrossRef]

21. Kihara, A.; Sano, T.; Iwaki, S.; Igarashi, Y. Transmembrane topology of sphingoid long-chain base-1-phosphate phosphatase, Lcb3p. Genes Cells 2003, 8, 525-535. [CrossRef]

22. Funato, K.; Vallée, B.; Riezman, H. Biosynthesis and trafficking of sphingolipids in the yeast Saccharomyces cerevisiae. Biochemistry 2002, 41, 15105-15114. [CrossRef]

23. Kondo, N.; Ohno, Y.; Yamagata, M.; Obara, T.; Seki, N.; Kitamura, T.; Naganuma, T.; Kihara, A. Identification of the phytosphingosine metabolic pathway leading to odd-numbered fatty acids. Nat. Commun. 2014, 5, 5338. [CrossRef]

24. Mayor, S.; Riezman, H. Sorting GPI-anchored proteins. Nat. Rev. Mol. Cell Biol. 2004, 5, 110-120. [CrossRef]

25. Bosson, R.; Guillas, I.; Vionnet, C.; Roubaty, C.; Conzelmann, A. Incorporation of ceramides into Saccharomyces cerevisiae glycosylphosphatidylinositol-anchored proteins can be monitored in vitro. Eukaryot. Cell 2009, 8, 306-314. [CrossRef] [PubMed]

26. Swain, E.; Stukey, J.; McDonough, V.; Germann, M.; Liu, Y.; Sturley, S.L.; Nickels, J.T. Yeast cells lacking the ARV1 gene harbor defects in sphingolipid metabolism: Complementation by human ARV1. J. Biol. Chem. 2002, 277, 36152-36160. [CrossRef] [PubMed]

27. Kajiwara, K.; Watanabe, R.; Pichler, H.; Ihara, K.; Murakami, S.; Riezman, H.; Funato, K. Yeast ARV1 is required for efficient delivery of an early GPI intermediate to the first mannosyltransferase during GPI assembly and controls lipid flow from the endoplasmic reticulum. Mol. Biol. Cell 2008, 19, 2069-2082. [CrossRef]

28. Sutterlin, C.; Doering, T.L.; Schimmoller, F.; Schroder, S.; Riezman, H. Specific requirements for the ER to Golgi transport of GPI-anchored proteins in yeast. J. Cell Sci. 1997, 110, 2703-2714. [CrossRef] [PubMed]

29. Bagnat, M.; Keränen, S.; Shevchenko, A.; Shevchenko, A.; Simons, K. Lipid rafts function in biosynthetic delivery of proteins to the cell surface in yeast. Proc Natl. Acad. Sci. USA 2000, 97, 3254-3259. [CrossRef]

30. Rodriguez-Gallardo, S.; Kurokawa, K.; Sabido-Bozo, S.; Cortes-Gomez, A.; Ikeda, A.; Zoni, V.; Aguilera-Romero, A.; Perez-Linero, A.M.; Lopez, S.; Waga, M.; et al. Ceramide chain length-dependent protein sorting into selective endoplasmic reticulum exit sites. Sci. Adv. 2020, 6, eaba8237. [CrossRef] [PubMed]

31. Funato, K.; Riezman, H. Vesicular and nonvesicular transport of ceramide from ER to the Golgi apparatus in yeast. J. Cell Biol. 2001, 155, 949-960. [CrossRef]

32. Levine, T.P.; Wiggins, C.A.; Munro, S. Inositol phosphorylceramide synthase is located in the Golgi apparatus of Saccharomyces cerevisiae. Mol. Biol. Cell 2000, 11, 2267-2281. [CrossRef] [PubMed] 
33. Sato, K.; Noda, Y.; Yoda, K. Kei1: A novel subunit of inositolphosphorylceramide synthase, essential for its enzyme activity and Golgi localization. Mol. Biol. Cell 2009, 20, 4444-4457. [CrossRef] [PubMed]

34. Lisman, Q.; Pomorski, T.; Vogelzangs, C.; Urli-Stam, D.; van Delwijnen, W.D.C.; Holthuis, J.C. Protein sorting in the late Golgi of Saccharomyces cerevisiae does not require mannosylated sphingolipids. J. Biol. Chem. 2004, 279, 1020-1029. [CrossRef]

35. Uemura, S.; Kihara, A.; Inokuchi, J.I.; Igarashi, Y. Csg1p and newly identified Csh1p function in mannosylinositol phosphorylceramide synthesis by interacting with Csg2p. J. Biol. Chem. 2003, 278, 45049-45055. [CrossRef]

36. Dickson, R.C.; Nagiec, E.E.; Wells, G.B.; Nagiec, M.M.; Lester, R.L. Synthesis of mannose-(inositol-P) 2-ceramide, the major sphingolipid in Saccharomyces cerevisiae, requires the IPT1 (YDR072c) gene. J. Biol. Chem. 1997, 272, 29620-29625. [CrossRef]

37. Schnabl, M.; Daum, G.; Pichler, H. Multiple lipid transport pathways to the plasma membrane in yeast. Biochim. Biophys. Acta (BBA)-Mol. Cell Biol. Lipids 2005, 1687, 130-140. [CrossRef] [PubMed]

38. Sawai, H.; Okamoto, Y.; Luberto, C.; Mao, C.; Bielawska, A.; Domae, N.; Hannun, Y.A. Identification of ISC1 (YER019w) as inositol phosphosphingolipid phospholipase C in Saccharomyces cerevisiae. J. Biol. Chem. 2000, 275, 39793-39798. [CrossRef]

39. De Avalos, S.V.; Okamoto, Y.; Hannun, Y.A. Activation and localization of inositol phosphosphingolipid phospholipase C, Isc1p, to the mitochondria during growth of Saccharomyces cerevisiae. J. Biol. Chem. 2004, 279, 11537-11545. [CrossRef] [PubMed]

40. Ohno, Y.; Kamiyama, N.; Nakamichi, S.; Kihara, A. PNPLA1 is a transacylase essential for the generation of the skin barrier lipid $\omega$-O-acylceramide. Nat. Commun. 2017, 8, 14610. [CrossRef] [PubMed]

41. Klug, L.; Daum, G. Yeast lipid metabolism at a glance. FEMS Yeast Res. 2014, 14, 369-388. [CrossRef]

42. Breslow, D.K. Sphingolipid homeostasis in the endoplasmic reticulum and beyond. Cold Spring Harb. Perspect. Biol. 2013, 5, a013326. [CrossRef]

43. Platt, F.M. Sphingolipid lysosomal storage disorders. Nature 2014, 510, 68-75. [CrossRef]

44. Teixeira, V.; Medeiros, T.C.; Vilaça, R.; Ferreira, J.; Moradas-Ferreira, P.; Costa, V. Ceramide signaling targets the PP2A-like protein phosphatase Sit4p to impair vacuolar function, vesicular trafficking and autophagy in Isc1p deficient cells. Biochim. Biophys. Acta (BBA)—Mol. Cell Biol. Lipids 2016, 1861, 21-33. [CrossRef]

45. Hurst, L.R.; Fratti, R.A. Lipid rafts, sphingolipids, and ergosterol in yeast vacuole fusion and maturation. Front. Cell Dev. Biol. 2020, 8, 539. [CrossRef]

46. Barbosa, A.D.; Osório, H.; Sims, K.J.; Almeida, T.; Alves, M.; Bielawski, J.; Amorim, M.A.; Moradas-Ferreira, P.; Hannun, Y.A.; Costa, V. Role for Sit4p-dependent mitochondrial dysfunction in mediating the shortened chronological lifespan and oxidative stress sensitivity of Isc1p-deficient cells. Mol. Microbiol. 2011, 81, 515-527. [CrossRef]

47. Malathi, K.; Higaki, K.; Tinkelenberg, A.H.; Balderes, D.A.; Almanzar-Paramio, D.; Wilcox, L.J.; Erdeniz, N.; Redican, F.; Padamsee, M.; Liu, Y.; et al. Mutagenesis of the putative sterol-sensing domain of yeast Niemann Pick C-related protein reveals a primordial role in subcellular sphingolipid distribution. J. Cell Biol. 2004, 164, 547-556. [CrossRef] [PubMed]

48. Conibear, E.; Cleck, J.N.; Stevens, T.H. Vps51p mediates the association of the GARP (Vps52/53/54) complex with the late Golgi t-SNARE Tlg1p. Mol. Biol. Cell 2003, 14, 1610-1623. [CrossRef] [PubMed]

49. Fröhlich, F.; Petit, C.; Kory, N.; Christiano, R.; Hannibal-Bach, H.K.; Graham, M.; Liu, X.; Ejsing, C.S.; Farese, R.V.; Walther, T.C. The GARP complex is required for cellular sphingolipid homeostasis. eLife 2015, 4, e08712. [CrossRef]

50. Tsuji, T.; Fujimoto, M.; Tatematsu, T.; Cheng, J.; Orii, M.; Takatori, S.; Fujimoto, T. Niemann-Pick type C proteins promote microautophagy by expanding raft-like membrane domains in the yeast vacuole. eLife 2017, 6, e25960. [CrossRef] [PubMed]

51. Esch, B.M.; Limar, S.; Bogdanowski, A.; Gournas, C.; More, T.; Sundag, C.; Walter, S.; Heinisch, J.J.; Ejsing, C.S.; André, B.; et al. Uptake of exogenous serine is important to maintain sphingolipid homeostasis in Saccharomyces cerevisiae. PLoS Genet. 2020, 16, e1008745. [CrossRef] [PubMed]

52. Han, S.; Lone, M.A.; Schneiter, R.; Chang, A. Orm1 and Orm2 are conserved endoplasmic reticulum membrane proteins regulating lipid homeostasis and protein quality control. Proc Natl. Acad. Sci. USA 2010, 107, 5851-5856. [CrossRef] [PubMed]

53. Breslow, D.K.; Collins, S.R.; Bodenmiller, B.; Aebersold, R.; Simons, K.; Shevchenko, A.; Ejsing, C.S.; Weissman, J.S. Orm family proteins mediate sphingolipid homeostasis. Nature 2010, 463, 1048-1053. [CrossRef]

54. Niles, B.J.; Powers, T. Plasma membrane proteins Slm1 and Slm2 mediate activation of the AGC kinase Ypk1 by TORC2 and sphingolipids in S. cerevisiae. Cell Cycle 2012, 11, 3745-3749. [CrossRef]

55. Fröhlich, F.; Moreira, K.; Aguilar, P.S.; Hubner, N.C.; Mann, M.; Walter, P.; Walther, T.C. A genome-wide screen for genes affecting eisosomes reveals Nce102 function in sphingolipid signaling. J. Cell Biol. 2009, 185, 1227-1242. [CrossRef]

56. Roelants, F.M.; Breslow, D.K.; Muir, A.; Weissman, J.S.; Thorner, J. Protein kinase Ypk1 phosphorylates regulatory proteins Orm1 and Orm2 to control sphingolipid homeostasis in Saccharomyces cerevisiae. Proc. Natl. Acad. Sci. USA 2011, 108, 19222-19227. [CrossRef] [PubMed]

57. Schmidt, O.; Weyer, Y.; Baumann, V.; Widerin, M.A.; Eising, S.; Angelova, M.; Schleiffer, A.; Kremser, L.; Lindner, H.; Peter, M.; et al. Endosome and Golgi-associated degradation (EGAD) of membrane proteins regulates sphingolipid metabolism. EMBO J. 2019, 38, e101433. [CrossRef]

58. Muir, A.; Ramachandran, S.; Roelants, F.M.; Timmons, G.; Thorner, J. TORC2-dependent protein kinase Ypk1 phosphorylates ceramide synthase to stimulate synthesis of complex sphingolipids. eLife 2014, 3, e03779. [CrossRef]

59. Aronova, S.; Wedaman, K.; Aronov, P.A.; Fontes, K.; Ramos, K.; Hammock, B.D.; Powers, T. Regulation of ceramide biosynthesis by TOR complex 2. Cell Metab. 2008, 7, 148-158. [CrossRef] [PubMed] 
60. Fröhlich, F.; Olson, D.K.; Christiano, R.; Farese, R.V., Jr.; Walther, T.C. Proteomic and phosphoproteomic analyses of yeast reveal the global cellular response to sphingolipid depletion. Proteomics 2016, 16, 2759-2763. [CrossRef]

61. Chauhan, N.; Han, G.; Somashekarappa, N.; Gable, K.; Dunn, T.; Kohlwein, S.D. Regulation of sphingolipid biosynthesis by the morphogenesis checkpoint kinase Swe1. J. Biol. Chem. 2016, 291, 2524-2534. [CrossRef]

62. Chauhan, N.; Visram, M.; Cristobal-Sarramian, A.; Sarkleti, F.; Kohlwein, S.D. Morphogenesis checkpoint kinase Swe1 is the executor of lipolysis-dependent cell-cycle progression. Proc Natl. Acad. Sci. USA 2015, 112, E1077-E1085. [CrossRef]

63. Meggio, F.; Pinna, L.A. One-thousand-and-one substrates of protein kinase CK2? FASEB J. 2003, 17, 349-368. [CrossRef]

64. Trembley, J.H.; Wang, G.; Unger, G.; Slaton, J.; Ahmed, K. Protein kinase CK2 in health and disease. Cell. Mol. Life Sci. 2009, 66, 1858-1867. [CrossRef]

65. Fresques, T.; Niles, B.; Aronova, S.; Mogri, H.; Rakhshandehroo, T.; Powers, T. Regulation of ceramide synthase by casein kinase 2-dependent phosphorylation in Saccharomyces cerevisiae. J. Biol. Chem. 2015, 290, 1395-1403. [CrossRef]

66. González, A.; Hall, M.N. Nutrient sensing and TOR signaling in yeast and mammals. EMBO J. 2017, 36, 397-408. [CrossRef] [PubMed]

67. Yan, G.; Shen, X.; Jiang, Y. Rapamycin activates Tap42-associated phosphatases by abrogating their association with Tor complex 1. EMBO J. 2006, 25, 3546-3555. [CrossRef] [PubMed]

68. Zimmermann, C.; Santos, A.; Gable, K.; Epstein, S.; Gururaj, C.; Chymkowitch, P.; Pultz, D.; Rødkær, S.V.; Clay, L.; Bjørås, M.; et al. TORC1 inhibits GSK3-mediated Elo2 phosphorylation to regulate very long chain fatty acid synthesis and autophagy. Cell Rep. 2013, 5, 1036-1046. [CrossRef] [PubMed]

69. Olson, D.K.; Fröhlich, F.; Christiano, R.; Hannibal-Bach, H.K.; Ejsing, C.S.; Walther, T.C. Rom2-dependent phosphorylation of Elo2 controls the abundance of very long-chain fatty acids. J. Biol. Chem. 2015, 290, 4238-4247. [CrossRef]

70. Swinnen, E.; Wilms, T.; Idkowiak-Baldys, J.; Smets, B.; De Snijder, P.; Accardo, S.; Ghillebert, R.; Thevissen, K.; Cammue, B.; De Vos, D.; et al. The protein kinase Sch9 is a key regulator of sphingolipid metabolism in Saccharomyces cerevisiae. Mol. Biol. Cell 2014, 25, 196-211. [CrossRef]

71. Urban, J.; Soulard, A.; Huber, A.; Lippman, S.; Mukhopadhyay, D.; Deloche, O.; Wanke, V.; Anrather, D.; Ammerer, G.; Riezman, H.; et al. Sch9 is a major target of TORC1 in Saccharomyces cerevisiae. Mol. Cell 2007, 26, 663-674. [CrossRef]

72. Loewith, R. TORC1 signaling in budding yeast. In The Enzymes; Academic Press: Cambridge, MA, USA, 2010; Volume 27, pp. $147-175$.

73. Takahara, T.; Maeda, T. Transient sequestration of TORC1 into stress granules during heat stress. Mol. Cell 2012, 47, 242-252. [CrossRef]

74. De Craene, J.O.; Bertazzi, D.L.; Bär, S.; Friant, S. Phosphoinositides, major actors in membrane trafficking and lipid signaling pathways. Int. J. Mol. Sci. 2017, 18, 634. [CrossRef] [PubMed]

75. Kobayashi, T.; Takematsu, H.; Yamaji, T.; Hiramoto, S.; Kozutsumi, Y. Disturbance of sphingolipid biosynthesis abrogates the signaling of Mss4, phosphatidylinositol-4-phosphate 5-kinase, in yeast. J. Biol. Chem. 2005, 280, 18087-18094. [CrossRef]

76. Gallego, O.; Betts, M.J.; Gvozdenovic-Jeremic, J.; Maeda, K.; Matetzki, C.; Aguilar-Gurrieri, C.; Beltran-Alvarez, P.; Bonn, S.; Fernández-Tornero, C.; Jensen, L.J.; et al. A systematic screen for protein-lipid interactions in Saccharomyces cerevisiae. Mol. Syst. Biol. 2010, 6, 430. [CrossRef]

77. Jesch, S.A.; Gaspar, M.L.; Stefan, C.J.; Aregullin, M.A.; Henry, S.A. Interruption of inositol sphingolipid synthesis triggers Stt4p-dependent protein kinase C signaling. J. Biol. Chem. 2010, 285, 41947-41960. [CrossRef] [PubMed]

78. Desrivieres, S.; Cooke, F.T.; Parker, P.J.; Hall, M.N. MSS4, a phosphatidylinositol-4-phosphate 5-kinase required for organization of the actin cytoskeleton in Saccharomyces cerevisiae. J. Biol. Chem. 1998, 273, 15787-15793. [CrossRef] [PubMed]

79. Audhya, A.; Emr, S.D. Stt4 PI 4-kinase localizes to the plasma membrane and functions in the Pkc1-mediated MAP kinase cascade. Dev. Cell 2002, 2, 593-605. [CrossRef]

80. Daquinag, A.; Fadri, M.; Jung, S.Y.; Qin, J.; Kunz, J. The yeast PH domain proteins Slm1 and Slm2 are targets of sphingolipid signaling during the response to heat stress. Mol. Cell. Biol. 2007, 27, 633-650. [CrossRef]

81. Levin, D.E. Regulation of cell wall biogenesis in Saccharomyces cerevisiae: The cell wall integrity signaling pathway. Genetics 2011, 189, 1145-1175. [CrossRef]

82. Dunayevich, P.; Baltanás, R.; Clemente, J.A.; Couto, A.; Sapochnik, D.; Vasen, G.; Colman-Lerner, A. Heat-stress triggers MAPK crosstalk to turn on the hyperosmotic response pathway. Sci. Rep. 2018, 8, 15168. [CrossRef]

83. Yamaguchi, Y.; Katsuki, Y.; Tanaka, S.; Kawaguchi, R.; Denda, H.; Ikeda, T.; Funato, K.; Tani, M. Protective role of the HOG pathway against the growth defect caused by impaired biosynthesis of complex sphingolipids in yeast Saccharomyces cerevisiae. Mol. Microbiol. 2018, 107, 363-386. [CrossRef]

84. Tani, M.; Funato, K. Protection mechanisms against aberrant metabolism of sphingolipids in budding yeast. Curr. Genet. 2018, 64, 1021-1028. [CrossRef]

85. Jenkins, G.M.; Richards, A.; Wahl, T.; Mao, C.; Obeid, L.; Hannun, Y. Involvement of yeast sphingolipids in the heat stress response of Saccharomyces cerevisiae. J. Biol. Chem. 1997, 272, 32566-32572. [CrossRef] [PubMed]

86. Sun, Y.; Miao, Y.; Yamane, Y.; Zhang, C.; Shokat, K.M.; Takematsu, H.; Kozutsumi, Y.; Drubin, D.G. Orm protein phosphoregulation mediates transient sphingolipid biosynthesis response to heat stress via the Pkh-Ypk and Cdc55-PP2A pathways. Mol. Biol. Cell 2012, 23, 2388-2398. [CrossRef] [PubMed] 
87. Friant, S.; Lombardi, R.; Schmelzle, T.; Hall, M.N.; Riezman, H. Sphingoid base signaling via Pkh kinases is required for endocytosis in yeast. EMBO J. 2001, 20, 6783-6792. [CrossRef]

88. Prinz, W.A.; Toulmay, A.; Balla, T. The functional universe of membrane contact sites. Nat. Rev. Mol. Cell Biol. 2020, 21, 7-24. [CrossRef]

89. Scorrano, L.; De Matteis, M.A.; Emr, S.; Giordano, F.; Hajnóczky, G.; Kornmann, B.; Lackner, L.L.; Pellegrini, L.; Reinisch, K.; Rizzuto, R.; et al. Coming together to define membrane contact sites. Nat. Commun. 2019, 10, 1-11. [CrossRef]

90. Manford, A.G.; Stefan, C.J.; Yuan, H.L.; MacGurn, J.A.; Emr, S.D. ER-to-plasma membrane tethering proteins regulate cell signaling and ER morphology. Dev. Cell 2012, 23, 1129-1140. [CrossRef]

91. West, M.; Zurek, N.; Hoenger, A.; Voeltz, G.K. A 3D analysis of yeast ER structure reveals how ER domains are organized by membrane curvature. J. Cell Biol. 2011, 193, 333-346. [CrossRef] [PubMed]

92. Pichler, H.; Gaigg, B.; Hrastnik, C.; Achleitner, G.; Kohlwein, S.D.; Zellnig, G.; Perktold, A.; Daum, G. A subfraction of the yeast endoplasmic reticulum associates with the plasma membrane and has a high capacity to synthesize lipids. Eur. J. Biochem. 2001, 268, 2351-2361. [CrossRef]

93. Quon, E.; Sere, Y.Y.; Chauhan, N.; Johansen, J.; Sullivan, D.P.; Dittman, J.S.; Rice, W.J.; Chan, R.B.; Paolo, G.D.; Beh, C.T.; et al. Endoplasmic reticulum-plasma membrane contact sites integrate sterol and phospholipid regulation. PLoS Biol. 2018, 16, e2003864. [CrossRef]

94. Nishimura, T.; Gecht, M.; Covino, R.; Hummer, G.; Surma, M.A.; Klose, C.; Arai, H.; Kono, N.; Stefan, C.J. Osh proteins control nanoscale lipid organization necessary for PI $(4,5)$ P2 synthesis. Mol. Cell 2019, 75, 1043-1057. [CrossRef] [PubMed]

95. Stefan, C.J.; Manford, A.G.; Baird, D.; Yamada-Hanff, J.; Mao, Y.; Emr, S.D. Osh proteins regulate phosphoinositide metabolism at ER-plasma membrane contact sites. Cell 2011, 144, 389-401. [CrossRef] [PubMed]

96. Chung, J.; Torta, F.; Masai, K.; Lucast, L.; Czapla, H.; Tanner, L.B.; Narayanaswamy, P.; Wenk, M.R.; Nakatsu, F.; De Camilli, P. PI4P/phosphatidylserine countertransport at ORP5-and ORP8-mediated ER-plasma membrane contacts. Science 2015, 349, 428-432. [CrossRef] [PubMed]

97. Zewe, J.P.; Wills, R.C.; Sangappa, S.; Goulden, B.D.; Hammond, G.R. SAC1 degrades its lipid substrate PtdIns4P in the endoplasmic reticulum to maintain a steep chemical gradient with donor membranes. eLife 2018, 7, e35588. [CrossRef]

98. de Saint-Jean, M.; Delfosse, V.; Douguet, D.; Chicanne, G.; Payrastre, B.; Bourguet, W.; Antonny, B.; Drin, G. Osh4p exchanges sterols for phosphatidylinositol 4-phosphate between lipid bilayers. J. Cell Biol. 2011, 195, 965-978. [CrossRef]

99. Von Filseck, J.M.; Vanni, S.; Mesmin, B.; Antonny, B.; Drin, G. A phosphatidylinositol-4-phosphate powered exchange mechanism to create a lipid gradient between membranes. Nat. Commun. 2015, 6, 6671. [CrossRef]

100. Omnus, D.J.; Manford, A.G.; Bader, J.M.; Emr, S.D.; Stefan, C.J. Phosphoinositide kinase signaling controls ER-PM cross-talk. Mol. Biol. Cell 2016, 27, 1170-1180. [CrossRef]

101. Schmidt, O.; Weyer, Y.; Sprenger, S.; Widerin, M.A.; Eising, S.; Baumann, V.; Angelova, M.; Loewith, R.; Stefan, C.J.; Hess, M.W.; et al. TOR complex 2 (TORC2) signaling and the ESCRT machinery cooperate in the protection of plasma membrane integrity in yeast. J. Biol. Chem. 2020, 295, 12028-12044. [CrossRef]

102. Rispal, D.; Eltschinger, S.; Stahl, M.; Vaga, S.; Bodenmiller, B.; Abraham, Y.; Filipuzzi, I.; Movva, N.R.; Aebersold, R.; Helliwell, S.B.; et al. Target of rapamycin complex 2 regulates actin polarization and endocytosis via multiple pathways. J. Biol. Chem. 2015, 290, 14963-14978. [CrossRef]

103. Riggi, M.; Bourgoint, C.; Macchione, M.; Matile, S.; Loewith, R.; Roux, A. TORC2 controls endocytosis through plasma membrane tension. J. Cell Biol. 2019, 218, 2265-2276. [CrossRef]

104. Wu, X.S.; Zhang, Z.; Zhao, W.D.; Wang, D.; Luo, F.; Wu, L.G. Calcineurin is universally involved in vesicle endocytosis at neuronal and nonneuronal secretory cells. Cell Rep. 2014, 7, 982-988. [CrossRef]

105. Stradalova, V.; Blazikova, M.; Grossmann, G.; Opekarová, M.; Tanner, W.; Malinsky, J. Distribution of cortical endoplasmic reticulum determines positioning of endocytic events in yeast plasma membrane. PLoS ONE 2012, 7, e35132. [CrossRef] [PubMed]

106. Qian, T.; Li, C.; He, R.; Wan, C.; Liu, Y.; Yu, H. Calcium-dependent and-independent lipid transfer mediated by tricalbins in yeast. J. Biol. Chem. 2021, 296, 100729. [CrossRef] [PubMed]

107. Thomas, F.B.; Omnus, D.J.; Bader, J.M.; Chung, G.H.; Kono, N.; Stefan, C.J. Tricalbin proteins regulate plasma membrane phospholipid homeostasis. bioRxiv 2021. [CrossRef]

108. Jorgensen, J.R.; Tei, R.; Baskin, J.M.; Michel, A.H.; Kornmann, B.; Emr, S.D. ESCRT-III and ER-PM contacts maintain lipid homeostasis. Mol. Biol. Cell 2020, 31, 1302-1313. [CrossRef]

109. Henne, W.M.; Buchkovich, N.J.; Emr, S.D. The ESCRT pathway. Dev. Cell 2011, 21, 77-91. [CrossRef]

110. Vietri, M.; Radulovic, M.; Stenmark, H. The many functions of ESCRTs. Nat. Rev. Mol. Cell. Biol. 2020, 21, 25-42. [CrossRef]

111. Mioka, T.; Guo, T.; Wang, S.; Tsuji, T.; Kishimoto, T.; Fujimoto, T.; Tanaka, K. Characterization of micron-scale protein-depleted plasma membrane domains in phosphatidylserine-deficient yeast cells. J. Cell Sci. 2021, 135, jcs256529. [CrossRef]

112. Cordeiro, R.M. Molecular structure and permeability at the interface between phase-separated membrane domains. J. Phys. Chem. B 2018, 122, 6954-6965. [CrossRef]

113. Liu, L.K.; Choudhary, V.; Toulmay, A.; Prinz, W.A. An inducible ER-Golgi tether facilitates ceramide transport to alleviate lipotoxicity. J. Cell Biol. 2017, 216, 131-147. [CrossRef] [PubMed]

114. Toulmay, A.; Prinz, W.A. A conserved membrane-binding domain targets proteins to organelle contact sites. J. Cell Sci. 2012, 125, 49-58. [CrossRef] 
115. Kama, R.; Kanneganti, V.; Ungermann, C.; Gerst, J.E. The yeast Batten disease orthologue Btn1 controls endosome-Golgi retrograde transport via SNARE assembly. J. Cell Biol. 2011, 195, 203-215. [CrossRef] [PubMed]

116. Henne, W.M.; Zhu, L.; Balogi, Z.; Stefan, C.; Pleiss, J.A.; Emr, S.D. Mdm1/Snx13 is a novel ER-endolysosomal interorganelle tethering protein. J. Cell Biol. 2015, 210, 541-551. [CrossRef]

117. Hariri, H.; Speer, N.; Bowerman, J.; Rogers, S.; Fu, G.; Reetz, E.; Datta, S.; Feathers, J.R.; Ugrankar, R.; Nicastro, D.; et al. Mdm1 maintains endoplasmic reticulum homeostasis by spatially regulating lipid droplet biogenesis. J. Cell Biol. 2019, 218, 1319-1334. [CrossRef]

118. Hanada, K.; Kumagai, K.; Yasuda, S.; Miura, Y.; Kawano, M.; Fukasawa, M.; Nishijima, M. Molecular machinery for non-vesicular trafficking of ceramide. Nature 2003, 426, 803-809. [CrossRef] [PubMed]

119. Kumagai, K.; Hanada, K. Structure, functions and regulation of CERT, a lipid-transfer protein for the delivery of ceramide at the ER-Golgi membrane contact sites. FEBS Lett. 2019, 593, 2366-2377. [CrossRef]

120. Kihara, A.; Igarashi, Y. Identification and characterization of a Saccharomyces cerevisiae gene, RSB1, involved in sphingoid long-chain base release. J. Biol. Chem. 2002, 277, 30048-30054. [CrossRef]

121. Heidler, S.A.; Radding, J.A. The AUR1 gene in Saccharomyces cerevisiae encodes dominant resistance to the antifungal agent aureobasidin A (LY295337). Antimicrob. Agents Chemother. 1995, 39, 2765-2769. [CrossRef]

122. Hashida-Okado, T.; Ogawa, A.; Endo, M.; Yasumoto, R.; Takesako, K.; Kato, I. AUR1, a novel gene conferring aureobasidin resistance on Saccharomyces cerevisiae: A study of defective morphologies in Aur1p-depleted cells. Mol. Gen. Genet. 1996, 251, 236-244.

123. Schorling, S.; Vallée, B.; Barz, W.P.; Riezman, H.; Oesterhelt, D. Lag1p and Lac1p are essential for the Acyl-CoA-dependent ceramide synthase reaction in Saccharomyces cerevisae. Mol. Biol. Cell 2001, 12, 3417-3427. [CrossRef] [PubMed]

124. Kajiwara, K.; Muneoka, T.; Watanabe, Y.; Karashima, T.; Kitagaki, H.; Funato, K. Perturbation of sphingolipid metabolism induces endoplasmic reticulum stress-mediated mitochondrial apoptosis in budding yeast. Mol. Microbiol. 2012, 86, 1246-1261. [CrossRef] [PubMed]

125. Eisenberg, T.; Büttner, S. Lipids and cell death in yeast. FEMS Yeast Res. 2014, 14, 179-197. [CrossRef]

126. Rego, A.; Duarte, A.M.; Azevedo, F.; Sousa, M.J.; Côrte-Real, M.; Chaves, S.R. Cell wall dynamics modulate acetic acid-induced apoptotic cell death of Saccharomyces cerevisiae. Microb. Cell 2014, 1, 303. [CrossRef]

127. Voynova, N.S.; Roubaty, C.; Vazquez, H.M.; Mallela, S.K.; Ejsing, C.S.; Conzelmann, A. Saccharomyces cerevisiae is dependent on vesicular traffic between the Golgi apparatus and the vacuole when inositolphosphorylceramide synthase Aur1 is inactivated. Eukaryot. Cell 2015, 14, 1203-1216. [CrossRef] [PubMed]

128. Cerantola, V.; Guillas, I.; Roubaty, C.; Vionnet, C.; Uldry, D.; Knudsen, J.; Conzelmann, A. Aureobasidin A arrests growth of yeast cells through both ceramide intoxication and deprivation of essential inositolphosphorylceramides. Mol. Microbiol. 2009, 71, 1523-1537. [CrossRef]

129. Epstein, S.; Castillon, G.A.; Qin, Y.; Riezman, H. An essential function of sphingolipids in yeast cell division. Mol. Microbiol. 2012, 84, 1018-1032. [CrossRef]

130. Su, W.C.; Lin, Y.H.; Pagac, M.; Wang, C.W. Seipin negatively regulates sphingolipid production at the ER-LD contact site. J. Cell Biol. 2019, 218, 3663-3680. [CrossRef] [PubMed]

131. Mao, C.; Xu, R.; Bielawska, A.; Szulc, Z.M.; Obeid, L.M. Cloning and characterization of a Saccharomyces cerevisiae alkaline ceramidase with specificity for dihydroceramide. J. Biol. Chem. 2000, 275, 31369-31378. [CrossRef]

132. Murakami, S.; Shimamoto, T.; Nagano, H.; Tsuruno, M.; Okuhara, H.; Hatanaka, H.; Tojo, H.; Kodama, Y.; Funato, K. Producing human ceramide-NS by metabolic engineering using yeast Saccharomyces cerevisiae. Sci. Rep. 2015, 5, 16319. [CrossRef]

133. Siskind, L.J.; Kolesnick, R.N.; Colombini, M. Ceramide forms channels in mitochondrial outer membranes at physiologically relevant concentrations. Mitochondrion 2006, 6, 118-125. [CrossRef]

134. Siskind, L.J.; Feinstein, L.; Yu, T.; Davis, J.S.; Jones, D.; Choi, J.; Zuckerman, J.E.; Tan, W.; Hill, R.B.; Hardwick, J.M.; et al. Anti-apoptotic Bcl-2 family proteins disassemble ceramide channels. J. Biol. Chem. 2008, 283, 6622-6630. [CrossRef]

135. Colombini, M. Ceramide channels and mitochondrial outer membrane permeability. J. Bioenerg. Biomembr. 2017, 49, 57-64. [CrossRef]

136. Rego, A.; Costa, M.; Chaves, S.R.; Matmati, N.; Pereira, H.; Sousa, M.J.; Moradas-Ferreira, P.; Hannun, Y.A.; Costa, V.; Côrte-Real, M. Modulation of mitochondrial outer membrane permeabilization and apoptosis by ceramide metabolism. PLoS ONE 2012, 7, e48571. [CrossRef] [PubMed]

137. Wissing, S.; Ludovico, P.; Herker, E.; Büttner, S.; Engelhardt, S.M.; Decker, T.; Link, A.; Proksch, A.; Rodrigues, F.; Corte-Real, M.; et al. An AIF orthologue regulates apoptosis in yeast. J. Cell Biol. 2004, 166, 969-974. [CrossRef] [PubMed]

138. Büttner, S.; Eisenberg, T.; Carmona-Gutierrez, D.; Ruli, D.; Knauer, H.; Ruckenstuhl, C.; Sigrist, C.; Wissing, S.; Kollroser, M.; Fröhlich, S.; et al. Endonuclease G regulates budding yeast life and death. Mol. Cell 2007, 25, 233-246. [CrossRef]

139. Martins, V.M.; Fernandes, T.R.; Lopes, D.; Afonso, C.B.; Domingues, M.R.; Côrte-Real, M.; Sousa, M.J. Contacts in death: The role of the ER-Mitochondria axis in acetic acid-induced apoptosis in yeast. J. Mol. Biol. 2019, 431, 273-288. [CrossRef]

140. Wang, H.; Sreenivasan, U.; Hu, H.; Saladino, A.; Polster, B.M.; Lund, L.M.; Gong, D.W.; Stanley, W.C.; Sztalryd, C. Perilipin 5, a lipid droplet-associated protein, provides physical and metabolic linkage to mitochondria. J. Lipid Res. 2011, 52, $2159-2168$. [CrossRef] 
141. Nguyen, T.B.; Olzmann, J.A. Lipid droplets and lipotoxicity during autophagy. Autophagy 2017, 13, 2002-2003. [CrossRef] [PubMed]

142. Benador, I.Y.; Veliova, M.; Liesa, M.; Shirihai, O.S. Mitochondria bound to lipid droplets: Where mitochondrial dynamics regulate lipid storage and utilization. Cell Metab. 2019, 29, 827-835. [CrossRef]

143. Faergeman, N.J.; Feddersen, S.; Christiansen, J.K.; Larsen, M.K.; Schneiter, R.; Ungermann, C.; Mutenda, K.; Roepstorff, P.; Knudsen, J. Acyl-CoA-binding protein, Acb1p, is required for normal vacuole function and ceramide synthesis in Saccharomyces cerevisiae. Biochem. J. 2004, 380, 907-918. [CrossRef]

144. Elbaz-Alon, Y.; Rosenfeld-Gur, E.; Shinder, V.; Futerman, A.H.; Geiger, T.; Schuldiner, M. A dynamic interface between vacuoles and mitochondria in yeast. Dev. Cell 2014, 30, 95-102. [CrossRef]

145. Ungermann, C. vCLAMPs_An intimate link between vacuoles and mitochondria. Curr. Opin. Cell Biol. $2015,35,30-36$. [CrossRef] [PubMed]

146. Hariri, H.; Rogers, S.; Ugrankar, R.; Liu, Y.L.; Feathers, J.R.; Henne, W.M. Lipid droplet biogenesis is spatially coordinated at ER-vacuole contacts under nutritional stress. EMBO Rep. 2018, 19, 57-72. [CrossRef] [PubMed]

147. Pan, X.; Roberts, P.; Chen, Y.; Kvam, E.; Shulga, N.; Huang, K.; Lemmon, S.; Goldfarb, D.S. Nucleus-vacuole junctions in Saccharomyces cerevisiae are formed through the direct interaction of Vac8p with Nvj1p. Mol. Biol. Cell 2000, 11, $2445-2457$. [CrossRef] [PubMed]

148. Otsu, M.; Toume, M.; Yamaguchi, Y.; Tani, M. Proper regulation of inositolphosphorylceramide levels is required for acquirement of low pH resistance in budding yeast. Sci. Rep. 2020, 10, 1-20. [CrossRef] [PubMed]

149. Matos, G.S.; Madeira, J.B.; Fernandes, C.M.; Dasilva, D.; Masuda, C.A.; Del Poeta, M.; Montero-Lomelí, M. Regulation of sphingolipid synthesis by the G1/S transcription factor Swi4. Biochim. Biophys. Acta (BBA)—Mol. Cell Biol. Lipids 2021, 1866, 158983. [CrossRef]

150. Wells, G.B.; Dickson, R.C.; Lester, R.L. Heat-induced elevation of ceramide in Saccharomyces cerevisiae via de novo synthesis. J. Biol. Chem. 1998, 273, 7235-7243. [CrossRef]

151. Piña, F.; Yagisawa, F.; Obara, K.; Gregerson, J.D.; Kihara, A.; Niwa, M. Sphingolipids activate the endoplasmic reticulum stress surveillance pathway. J. Cell Biol. 2018, 217, 495-505. [CrossRef]

152. Fabri, J.H.T.M.; de Sá, N.P.; Malavazi, I.; Del Poeta, M. The dynamics and role of sphingolipids in eukaryotic organisms upon thermal adaptation. Prog. Lipid Res. 2020, 80, 101063. [CrossRef]

153. Clay, L.; Caudron, F.; Denoth-Lippuner, A.; Boettcher, B.; Frei, S.B.; Snapp, E.L.; Barral, Y. A sphingolipid-dependent diffusion barrier confines ER stress to the yeast mother cell. eLife 2014, 3, e01883. [CrossRef]

154. Yabuki, Y.; Ikeda, A.; Araki, M.; Kajiwara, K.; Mizuta, K.; Funato, K. Sphingolipid/Pkh1/2-TORC1/Sch9 signaling regulates ribosome biogenesis in tunicamycin-induced stress response in yeast. Genetics 2019, 212, 175-186. [CrossRef] [PubMed]

155. Guan, X.L.; Souza, C.M.; Pichler, H.; Dewhurst, G.; Schaad, O.; Kajiwara, K.; Wakabayashi, H.; Ivanova, T.; Castillon, G.A.; Piccolis, M.; et al. Functional interactions between sphingolipids and sterols in biological membranes regulating cell physiology. Mol. Biol. Cell 2009, 20, 2083-2095. [CrossRef]

156. Breslow, D.K.; Weissman, J.S. Membranes in balance: Mechanisms of sphingolipid homeostasis. Mol. Cell 2010, 40, 267-279. [CrossRef] [PubMed]

157. Simons, K.; Sampaio, J.L. Membrane organization and lipid rafts. Cold Spring Harb. Perspect. Biol. 2011, 3, a004697. [CrossRef] [PubMed]

158. Murley, A.; Yamada, J.; Niles, B.J.; Toulmay, A.; Prinz, W.A.; Powers, T.; Nunnari, J. Sterol transporters at membrane contact sites regulate TORC1 and TORC2 signaling. J. Cell Biol. 2017, 216, 2679-2689. [CrossRef]

159. Gatta, A.T.; Levine, T.P. Piecing Together the Patchwork of Contact Sites. Trends Cell Biol. 2017, 27, 214-229. [CrossRef]

160. Tsuji, T.; Fujimoto, T. Lipids and lipid domains of the yeast vacuole. Biochem. Soc. Trans. 2018, 46, 1047-1054. [CrossRef] 